\title{
Healthcare professionals' perception of quality of care of patients with cardiac disease in Nigeria: Implication for clinical guideline, inter-professional education
} and team work

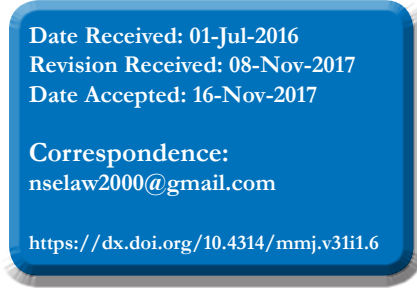

\section{Nse AyoOluwa Odunaiya ${ }^{1}$, Aderonke Omobonike Akinpelu $^{1}$, Susan Ogwu ${ }^{1}$, Akinuemi Aje ${ }^{2}$}

1. Department of Physiotherapy, University of Ibadan

2. Department of Medicine, University of Ibadan, Ibadan, Nigeria.

\begin{abstract}
Background
Heart disease is one of the leading chronic conditions posing a major and growing threat to the public. Studies on quality of care given to patients with heart diseases in Nigeria are not available. The purpose of this study was to explore healthcare professionals' perception of quality of care of patients with heart disease at a tertiary hospital in Nigeria.

Methods

A mixed method design was utilized in this study. Twenty eight healthcare professionals consisting of cardiologists, nurses, physiotherapists and dieticians were recruited into the study through purposive sampling technique. A questionnaire developed and validated from existing questionnaire was used to survey the health care professionals' perception of care and qualitative design was further used to explore their perceptions of care. The data were analyzed using descriptive statistics of percentages and graphs. The qualitative data were analyzed using thematic analysis. Quality of care was assessed through structure, process and outcome of care indices.

Results

The mean age of the healthcare professionals was 38.46 \pm 8.988 years. 19 (66.7\%) reported that there were treatment guidelines for cardiac disease management but there was no system for internal quality assurance. $18(95 \%)$ out of these 19 healthcare professionals reported that the treatment guidelines were either never applied or not applied regularly during treatment. Other areas that were perceived as poor were poor teamwork, poor staff strength, inadequate equipment, and inadequate consultation with staff during procurement of medical supplies Conclusion

Quality of care for cardiac patients in a Nigerian tertiary hospital was perceived as sub-optimal. There is a need for the improvement of the structure and process of quality of care to enhance quality of care for cardiac patients in Nigeria.

Key words: quality of care, health care professionals, perceptions, cardiac patients
\end{abstract}

\section{Introduction}

Heart disease is one of the primary chronic conditions that pose a major and growing threat to the public health and is a major contributor to the burden of disease in low- and middle income countries ${ }^{1-2}$. Every year, 17.1 million lives are claimed by heart diseases and $82 \%$ of these are from developing countries ${ }^{3}$. In developed countries, coronary heart disease is a leading cause of death ${ }^{4-5}$ while in Africa, hypertensive heart disease, dilated cardiomyopathy and rheumatic heart disease are high on the list of causes of heart failure and death ${ }^{6-8}$. In Nigeria, heart disease is the $4^{\text {th }}$ among the top 20 diseases responsible for mortality ${ }^{9}$. The increase in prevalence and incidence of heart disease in Nigeria is due to increasing prevalence of cardiovascular disease risk factors particularly hypertension. The authors observe that Management of heart disease poses a great challenge to Nigeria because of limited resources for acute care for patients with heart diseases. Management for heart disease involve prevention, screening, diagnosis, medications, surgery, palliative care including a full continuum of acute or ongoing care with goals of stabilizing the condition immediately, controlling symptoms over the long term, and cardiac rehabilitation. Hence the complex nature of heart diseases requires optimal collaboration and coordination between healthcare professionals to deliver quality care ${ }^{10-12}$. Cardiac rehabilitation forms an integral part of standard care for patients with heart diseases. It entails comprehensive secondary preventive strategies for managing risk factors, nutritional, psychological, behavioral and social factors aimed at preventing the progression of the diseases and improving patient outcomes ${ }^{13}$. Evidence shows that strategies in cardiac rehabilitation can slow, stabilize or cause a reverse in the progression of atherosclerosis and reduce cardiovascular events ${ }^{14-19}$. Effective collaboration of health care professionals in the care of patients with heart disease will usually result in good quality care for the patient ${ }^{20}$. Quality of care for patients with heart diseases implies the delivery of services in a way that is safe, timely, patient centered, efficient, and equitable ${ }^{21}$. The growing demands to provide care appropriate to the needs of people with heart disease are significant. Private and public policymakers 
are continually examining and introducing multidisciplinary efforts to improve the quality and cost effectiveness of care for patients with heart diseases. Therefore assessing quality of care forms an aspect of a comprehensive approach to formulating evidence-based goals for patient care and is a significant component of the continuous quality improvement program ${ }^{22-25}$. Most approaches to evaluating the quality of care is through the use of indicators, derived from combining the measures of structure, process and outcome of care ${ }^{26}$. Research on quality of care for patients with heart diseases is routinely conducted in developed countries with the aim of improving quality of care ${ }^{21}$. Although a few studies on quality of care have been conducted in Nigeria ${ }^{27-30}$, none of them focused on quality of care of patients with cardiac diseases. Since heart disease is an important condition of public health concern, it is important to investigate the quality of care in Nigeria. In developing countries like Nigeria where patients are not knowledgeable enough to know what the healthcare professionals are expected to do for them, certain dimensions of care are best assessed by health professionals themselves. Patients' perception of quality of care has also been explored and will make another manuscript.

\section{Methods}

\section{Ethical consideration}

Prior to the commencement of the study, ethical approval was obtained from the Research Ethics Committee of the University of Ibadan/University College Hospital Ibadan, with approval no: UI/EC/14/0112. The purpose of the study was explained to the healthcare professionals involved in the care of cardiac patients, and informed consent to participate in this study was obtained from all the participants.

\section{Research design}

The study employed a mixed method design.

\section{Participants}

Participants of this study comprised cardiologist in training (senior registrars), nurses, dieticians, and physiotherapists. They are health care providers involved in the care of patients with cardiac disease at a teaching hospital in Nigeria.

\section{Sampling and sample size calculation}

Purposive sampling technique was used to select the participants of the study. Population study was initially planned, however, all cardiologists, nurses, physiotherapists and dieticians were not available within the timeframe of the research to give their consent, 28 healthcare professionals (about 60\%) of health professionals involved in the multidisciplinary team care of cardiac patients participated in the study. The healthcare professionals comprised four cardiologists in training (senior registrars), eight physiotherapists, twelve nurses and four dieticians with at least one year experience in cardiac management.

\section{Healthcare professionals'perception of quality of care}

\section{questionnaire}

A specifically developed and validated questionnaire by authors was used to measure the healthcare professionals' perception of quality of care given to patients with heart diseases at the $\mathrm{UCH}$, Ibadan. The questionnaire is a 19 item profile scale with four subscales which are demographic subscale, structure of quality of care subscale, process of quality of care subscale and outcome of quality of care subscale. The structure of quality of care subscale sought to find out the healthcare professionals' perception on training experience, certification, provision of regular update for evidence based practice, system for internal quality assurance, treatment guideline and application. The process of quality of care subscale assessed the healthcare professionals' perception on risk assessment, prevention and treatment of heart disease. The outcome of quality of care subscale assessed the healthcare professionals' perception on control of risk factors, mortality, and survival. The internal consistency of the items of the questionnaires was tested using Cronbach's alpha coefficient. Cronbach's alpha coefficient for the developed questionnaire for health care professionals is 0.83 . For easy description, response options such as disagree, strongly disagree, and neither agree nor disagree were grouped as poor quality of care while responses such as agree and strongly agree were categorized as good quality of care. The questionnaire was given to the health care professionals to complete after which it was collected immediately or when the health care professional had agreed to return it to one of the authors.

\section{Focus group discussion}

Two focus group discussions were conducted for nurses. Each session consisted of three nurses and lasted about 90 minutes. Consent to audio tape discussions was obtained. Notes were taken by an independent observer. Questions on the equipment and facilities, process of treatment and outcome of care were asked during the discussion. The moderator asked other questions and used probes as necessary to stimulate the discussion. The focus group discussions were conducted in English which is the official language spoken in Nigeria. The recorded information from the discussion was transcribed verbatim by a trained independent transcriptionist.

\section{Interviews}

In-depth interviews were conducted for other health care professionals who the authors could not bring together for focus group discussion. They were physiotherapist, dietician, and senior registrars in cardiology. Questions on the structure, process of treatment and outcome of care were asked during the interview. Each session lasted 60-90 minutes. The interview was conducted in English which is the official language spoken in Nigeria. The recorded information was transcribed verbatim by a transcriptionist.

\section{Results}

\section{Response rate}

All copies of the questionnaires given to health care professionals were returned, giving 100\% response rate.

\section{Profile and characteristics of the participants}

A total of 28 health care professionals participated in the survey. They were 4 cardiologists in training (senior registrars), eight physiotherapists, twelve nurses and four dieticians. Their mean age was $38.46 \pm 8.988$ years. There 
were 10 males and 18 females.

\section{Structure of quality of care}

Of the 28 healthcare professionals, $18(64.3 \%)$ had a form of training in cardiac management, 17 (60.7\%) reported that evidence based practice update courses were not provided regularly, and $19(66.7 \%)$ reported that there were treatment guidelines for cardiac disease management available at the cardiac unit but there was no system for internal quality assurance. Out of these 19 healthcare professionals, 18 $(95 \%)$ reported that the treatment guidelines were either never applied or not applied regularly during treatment as shown in table 1.

Table 1: Healthcare professionals' perception of structure of care

\begin{tabular}{|c|c|c|}
\hline Constructs of Structure & Frequency & Percentage \\
\hline $\begin{array}{l}\text { Ever had training in cardiac } \\
\text { disease management } \\
\text { yes } \\
\text { No }\end{array}$ & $\begin{array}{l}18 \\
10\end{array}$ & $\begin{array}{l}64.3 \\
35.7\end{array}$ \\
\hline $\begin{array}{l}\text { Had training } \\
\text { in the past } 5 \text { years }\end{array}$ & 16 & 57.1 \\
\hline $\begin{array}{l}\text { Provision of } \\
\text { regular update } \\
\text { Yes } \\
\text { No }\end{array}$ & $\begin{array}{l}17 \\
11\end{array}$ & $\begin{array}{l}60.7 \\
39.3\end{array}$ \\
\hline $\begin{array}{l}\text { System for } \\
\text { internal quality assurance } \\
\text { Yes } \\
\text { No }\end{array}$ & $\begin{array}{l}9 \\
19\end{array}$ & $\begin{array}{l}32.1 \\
67.9\end{array}$ \\
\hline $\begin{array}{l}\text { Have treatment } \\
\text { guideline } \\
\text { Yes } \\
\text { No } \\
\text { f yes, how is } \\
\text { guideline applied } \\
\text { Regularly applied } \\
\text { Never applied } \\
\text { Not applied regularly }\end{array}$ & $\begin{array}{l}1 \\
14 \\
4\end{array}$ & $\begin{array}{l}5.3 \\
73.7 \\
21.0\end{array}$ \\
\hline
\end{tabular}

\section{Process of quality of care}

Table 2 shows healthcare professionals' perception of process; $18(64 \%)$ healthcare professionals perceived process as good while $10(36 \%)$ perceived it as poor.

\section{Outcome of quality of care}

Table 3 shows healthcare professionals' perception of outcome $67.9 \%$ of the healthcare professionals reported having positive outcomes of care in control of risk of cardiovascular event while $32.1 \%$ of them perceived outcome as negative. Similar findings are observed in reduced mortality rate and increasing survival rate.

\section{Structure of care}

All the healthcare professionals were of the opinion that there was no sufficient equipment to give patients with heart diseases the quality of care stipulated by international guidelines. A physiotherapist had this to say:

"A patient that has post MI was referred and I found out that simple things like pulse oximeter and the heart rate monitor to measure the patient's heart rate and oxygen saturation were not available in the department. For a patient like that, you will want the most recent ECG to be available, so you know the state of the heart before you intervene. Most likely, the last ECG you might see is the one done 4-5 days ago, which is not current. We don't have pulmonary function machine in our unit. What we depend on before the surgery is just the chest X-ray. But we know that the Chest X-ray can be clear, but the pulmonary function may be impaired.... Although we have one pulmonary function machine at Medicine department presently, but how accessible is it?"

A nurse had this to say:

"Like the monitor in ICU, you remove it from one patient to the other patient. So what if anything goes wrong with the other patient that it has been removed from? If you have a patient that is dyspnoeic that is on oxygen and you have another that is very bad, you have to remove the oxygen from the one that can still manage and transfer it to the other one whose condition is worse. If the two of them are dying, they die together and that really makes you feel frustrated." "When I was in Accident and Emergency unit, we don't have stethoscope. So you come with your own personal stethoscope if you want to really work."

A senior registrar cardiologist had this to say:

"The ER has to change; we need to stock it with different types of resuscitatory gadgets especially for cardiac resuscitation and emergency. We have the ECG machine already and then possibly the catherization lab may even be located close to the A and $E$ so that the door to get there will be shortened as much as possible." A dietician had this to say:

"Starting from what the cooks use for cooking, a lot of cooking wares are obsolete, are no more in use. Nobody is repairing them; we are making use of what we can. So if I have the opportunity to see the management and if they are really ready, there are a lot of things we need in order to work, even our food stuffs, we need materials, you don't restrict dieticians".

Inadequate consultations with healthcare professionals during procurement of medical supplies were also pointed out as a factor that may be limiting their effort to provide quality care to patients with cardiac conditions. The nurses had this to say:

"The management wouldn't come to us that are the end users. When we are making requests, my "immediate bosses in nursing" will say don't write "four" because you know that if you write "four" they won't supply anything; as if it is for our personal use. If they can actually come to the ward personally and talk to the people that are actually using these things... what are the things that you will need, that you believe we can get?

"If anything should be changed, they should go to the people using it, not just the contractors." "In an environment like these where there are a lot of bureaucracy that you have to pass through before things can be done.... writing letters, waiting and the patient is there suffering. You really want to put in your best but they are a lot of barriers." 
Table 2: Healthcare professionals' perception of process of care

\begin{tabular}{|c|c|c|c|c|c|}
\hline Construct of Process & SD & DA & NDNA & A & SA \\
\hline & $1(3.6)$ & $0(0)$ & $7(25.0)$ & $7(25.0)$ & $13(46.4)$ \\
\hline Full blood count test & $0(0)$ & $0(0)$ & $2(7.1)$ & $5(17.9)$ & $21(75.0)$ \\
\hline Lipid profile test & $0(0)$ & $1(3.6)$ & $3(10.7)$ & $9(32.1)$ & $15(53.6)$ \\
\hline Blood glucose test & $0(0)$ & $1(3.6)$ & $6(21.4)$ & $8(28.6)$ & $13(46.4)$ \\
\hline Renal test & $0(0)$ & $1(3.6)$ & $10(35.7)$ & $8(28.6)$ & $9(32.1)$ \\
\hline Liver test & $0(0)$ & $4(14.3)$ & $8(28.6)$ & $9(32.1)$ & $7(25.0)$ \\
\hline Thyroid function test & $0(0)$ & $0(0)$ & $5(17.9)$ & $9(32.1)$ & $14(50.0)$ \\
\hline Exercise tolerance test & $0(0)$ & $0(0)$ & $1(3.6)$ & $2(7.1)$ & $25(89.3)$ \\
\hline Standard ECG test & $0(0)$ & $0(0)$ & $0(0)$ & $1(3.6)$ & $27(96.4)$ \\
\hline Blood pressure measurement & $1(3.6)$ & $3(10.7)$ & $5(17.9)$ & $8(28.6)$ & $11(39.3)$ \\
\hline Cardiac catheterization & $0(0)$ & $2(7.1)$ & $14(50.0)$ & $7(25.0)$ & $5(17.9)$ \\
\hline Pharmacological stress test & $0(0)$ & $0(0)$ & $6(21.4)$ & $11(39.3)$ & $11(39.3)$ \\
\hline Electrophysiological studies & $0(0)$ & $0(0)$ & $2(7.1)$ & $8(28.6)$ & $18(64.3)$ \\
\hline Chest X-ray & $0(0)$ & $0(0)$ & $1(3.6)$ & $2(7.1)$ & $25(89.3)$ \\
\hline Echocardiogram & $0(0)$ & $1(3.6)$ & $1(3.6)$ & $8(28.5)$ & $18(64.3)$ \\
\hline Explanation of cardiovascular risk & $0(0)$ & $0(0)$ & $0(0)$ & $6(21.4)$ & $22(78.6)$ \\
\hline Counselling on smoking cessation & $1(3.6)$ & $0(0)$ & $0(0)$ & 5 (17.9) & $22(78.6)$ \\
\hline $\begin{array}{l}\text { Counselling on moderation of alcohol } \\
\text { consumption }\end{array}$ & $0(0)$ & $0(0)$ & $0(0)$ & $5(17.9)$ & $23(82.1)$ \\
\hline Counselling on weight management & $0(0)$ & $0(0)$ & $0(0)$ & $5(17.9)$ & $23(82.1)$ \\
\hline Counselling on blood pressure control & $0(0)$ & $1(3.6)$ & $1(3.6)$ & 5 (17.9) & $21(75.0)$ \\
\hline Counselling on physical activity & $0(0)$ & $0(0)$ & $0(0)$ & $6(21.4)$ & $22(78.6)$ \\
\hline Information on medication & $0(0)$ & $1(3.6)$ & $1(3.6)$ & $8(28.6)$ & $18(64.3)$ \\
\hline Lipid management & $0(0)$ & $2(7.1)$ & $5(17.9)$ & $8(28.6)$ & $13(46.4)$ \\
\hline Diabetes management & $0(0)$ & $1(3.6)$ & $10(35.7)$ & $9(32.1)$ & $8(28.6)$ \\
\hline Reperfusion therapy & $0(0)$ & $1(3.6)$ & $2(7.1)$ & $11(39.3)$ & $14(50.0)$ \\
\hline Cardiac rehabilitation & $2(7.1)$ & $2(7.1)$ & $7(25.0)$ & $6(21.4)$ & $11(39.3)$ \\
\hline Palliative care & $0(0)$ & $1(3.6)$ & $3(10.7)$ & $8(28.6)$ & $16(57.1)$ \\
\hline Drug therapy using evidence based guidelines & $0(0)$ & $1(3.6)$ & $6(21.4)$ & $8(28.6)$ & $13(46.4)$ \\
\hline Surgery using evidence based guidelines & $0(0)$ & $0(0)$ & $0(0)$ & $4(14.3)$ & 24 (85.7) \\
\hline $\begin{array}{l}\text { Effective communication with patients on the } \\
\text { diagnosis and treatment options } \\
\text { Effective communication with other health care } \\
\text { professionals }\end{array}$ & $0(0)$ & $1(3.6)$ & $0(0)$ & $7(25.0)$ & $20(71.4)$ \\
\hline Skillful performance of technical procedures & $0(0)$ & $0(0)$ & $0(0)$ & $8(28.6)$ & $20(71.4)$ \\
\hline $\begin{array}{l}\text { pect and compassion for patients and their } \\
\text { lies }\end{array}$ & $0(0)$ & $1(3.6)$ & $1(3.6)$ & $10(35.7)$ & $16(57.1)$ \\
\hline $\begin{array}{l}\text { Tamilles } \\
\text { Maintenance of quality medical docum }\end{array}$ & $0(0)$ & $1(3.6)$ & $0(0)$ & $7(25.0)$ & $20(71.4)$ \\
\hline Coordinating care effectively for patien & $0(0)$ & $1(3.6)$ & $1(3.6)$ & $6(21.4)$ & $20(71.4)$ \\
\hline $\begin{array}{l}\text { Coordinatıng care effectively for patien } \\
\text { Handling consultation request timely }\end{array}$ & $0(0)$ & $0(0)$ & $2(7.1)$ & $8(28.6)$ & $18(64.3)$ \\
\hline $\begin{array}{l}\text { Hanallng consultation request timely } \\
\text { Performing discharge planning effectively }\end{array}$ & $0(0)$ & $1(3.6)$ & $2(7.1)$ & $6(21.4)$ & 19 (67.9) \\
\hline $\begin{array}{l}\text { Pertorming alscharge planning enectively } \\
\text { Designing care process to suit patients }\end{array}$ & $0(0)$ & $1(3.6)$ & $0(0)$ & $7(25.0)$ & $20(71.4)$ \\
\hline & $0(0)$ & $0(0)$ & $0(0)$ & $9(32.1)$ & 19 (67.9) \\
\hline
\end{tabular}

Correct diagnosis and appropriate treatments

DA = Disagree, NDNA= Neither Disagree Nor Agree, $A=$ Agree, $S A=$ Strongly Agree 
Table 3: Healthcare professionals' perception on outcome of care provided at the UCH

$\begin{array}{lll}\text { Constructs of Outcome } & \text { Frequency } & \text { Percentage } \\ \text { Control of risk of } & & \\ \text { cardiovascular events } & 1 & 3.6 \\ \text { Excellent } & 8 & 28.6 \\ \text { Very good } & 10 & 35.7 \\ \text { Good } & 3 & 10.7 \\ \text { Poor } & 6 & 21.4 \\ \text { Don't know } & & \\ & & \\ \text { Reduce mortality rates } & 1 & 3.6 \\ \text { Excellent } & 4 & 14.3 \\ \text { Very good } & 12 & 42.9 \\ \text { Good } & 4 & 14.3 \\ \text { Poor } & 7 & 25.0 \\ \text { Don't know } & & \\ \text { Increasing survival rate } & 2 & 7.1 \\ \text { Excellent } & 7 & 25.0 \\ \text { Very good } & 10 & 35.7 \\ \text { Good } & 3 & 10.7 \\ \text { Poor } & 6 & 21.4 \\ \text { Don't know } & & \end{array}$

Poor staff strength was highlighted during the interview as it was observed that some departments were understaffed and overworked so, under such circumstances, low work output may be expected especially when the ratio of care provider to patient is not commensurate.

"During some afternoon shifts there are 2 nurses to 28 patients".

They also highlighted the need for more doctors to reduce the waiting time of patients.

"Some patients don't want to come because of time factor. They will come and spend the whole day. So sometimes they may not want to keep their appointment and by the time they will present, their condition will be worse." "Some people will come and they are given a month's appointment and they will be complaining, what if I die before that time? But the fact remains that you can't give more than 10 new cases to a consultant cardiologist to see in a day." "if there could be more consultants, at least if some people are doing ward rounds, some people will be around at the same time in the clinic, so that it will not be after the round that they will come to the clinic. If there could be more doctors, more nurses, and more pharmacists too, the patients will come and go on time".

\section{Process of care}

Healthcare professionals believed they had the skills to manage cardiac conditions. They pointed out that they have adopted strategies such as updating themselves with educational materials, conducting seminars in their unit and attending conferences and workshop within the country as much as possible.

"We have seminars, sometimes; we look into journals to see what is happening. Somebody brings a topic and we go and research on it; then we present it. So within the confines of what we have, we are trying to develop ourselves. There is ongoing training most of the time; usually during ward rounds occasionally during clinics to make sure knowledge is not lost. As far as Nigeria is concerned, people want to come over here for update courses and everybody sees UCH Ibadan as better than other places in Nigeria."
However, the healthcare professionals noted that though they have developed skills for managing cardiac conditions, most of them are not specifically specialized in cardiac care. They also suggested that the training of a team instead of a single professional will improve the quality of care given to patients with cardiac conditions and also enhance communication within the team.

"one thing is, you having interest for going to attend seminars that will improve your output in whatever you are doing; but by the time you are saying you want to go these year, you want to go next year, they will ask. you "are you the only one?" even if you want to spend your own money, you might not be released from duty to attend such training. Because you might just be two on afternoon duty and you are saying you want to go for... so who is going to assist the other person? For logistic reasons, except you will now sacrifice your own time... May be you do night and go with your own night off and that will not be encouraging." "The whole team needs training to be able to perform their role effectively. Once a team is trained, communication will flow. If you are trained together, communication will flow."

Inter-professional team work was perceived as poor among healthcare providers and this was clearly expressed by a senior registrar cardiologist:

The problem I feel we have now is the problem of team work. If a patient is about to go for surgery, everybody should come together. Somebody presents the patient, and then from your own point of view, you say what you are going to do. We have a lot of patients that are admitted; about to go in for surgery that physiotherapist does not see. It is at the post-op stage that the physiotherapist sees the patient. The things you are supposed to have taught the patient before surgery, you start teaching them post-surgery. For example, teaching the patient the way to cough. The patient has so many things to learn which may overwhelm the patient at the post-op stage of a major surgery, and this will affect your outcome. So, the major challenge is team work: early referral. I think the problem is communication gap

"T know that there is a lot of ego amongst the various health care teams that makes interpersonal relationship difficult to take place, everybody is a lord in his own domain and may not want to refer to the other in the interest of the patient, and you just want to do what you want to do. So I think that there is enough attitude issue among us that needs to go."

\section{Outcome of care}

Healthcare providers perceived the quality of care given to cardiac patients as inadequate but indicated that within the constraint of available resources, the quality of care was fair. "We are doing our best within the constraint of the available resources to get the best for our patient and to get the best training for our health personnel. I will say that within the constraints of the resources and facilities available, we have the knowledge required to run the system within our territory as properly as possible. As regards non-interventional care which is what I will say is our strength here, we have not lagged behind".

Some healthcare professionals also had this to say about the outcome of some of their treatment because of structural limitation:

"Sometimes we get disappointed"

"....It is going to affect care at the end of the day because you will be limited in what you can do. You will also be limited in your outcome. We don't have what is needed to give the best" 


\section{Discussion}

This is the first study assessing quality of care of cardiac patients at a Nigeria's best cardiac center using a mixed method design.

\section{Structure of care}

Findings from the quantitative component of this study showed that many of the healthcare professionals perceived some of the items in the domain of structure of quality of care for heart disease at the University College Hospital Ibadan $(\mathrm{UCH})$ as good and some as poor. Most of the healthcare professionals reported they had a form of training in cardiac care and many reported that there was some form or procedure for updating evidence based practice in their units. Having relevant knowledge and being professionally up to date are considered vital ${ }^{31}$ as that may help the healthcare professionals to provide better process and outcome of care. However, being certified or undergoing training alone cannot predict the quality of care. Many of the health care professionals reported that treatment guidelines for cardiac disease management were available but the treatment guidelines were either never applied or not applied regularly during treatment. This conforms to a similar study by Beauchesne et al, ${ }^{32}$ which revealed that healthcare professional utilization of treatment guidelines were suboptimal. Health professionals also reported that there was no system for internal quality assurance. This further explains why treatment guidelines where not used regularly when treating patients. The qualitative component revealed that the structure of quality of care for patients with heart disease was perceived as poor by the healthcare professionals due to poor staff strength and low training opportunity for healthcare professionals other than doctors to specialize in the management of patients with heart disease. Healthcare professionals indicated that although major facilities like the cardiac catherization laboratory were on ground, basic medical supplies like pulse oximeter, resuscitation drugs, pulmonary function test machine, and stethoscope amongst other treatment requirements were not adequate or readily available for use. They felt this was because the hospital management does not involve them adequately in infrastructural planning and procurement of medical supplies. These findings are supported by Kedwall et $\mathrm{al}^{33}$.

\section{Process of care}

Most of the constructs of process of care which entails risk assessment, prevention and treatment of care were perceived as having good quality while others such as team work was poor. Though the healthcare professionals were not regularly applying treatment guidelines as was observed in the results from structure of care, the results from process of care showed some form of adherence to a treatment protocol when delivering treatment. This may be linked to their basic training in the management of heart diseases. Evidence shows that the application of treatment guidelines affects the process and sometimes the outcome of care ${ }^{34}$. This implies that ensuring regular application of guidelines during treatment will serve as a good tool in improving process of care. This finding conforms to the findings from some other studies where healthcare professionals perceive the process of care as having good quality ${ }^{35-36}$. Findings from qualitative component shows that waiting time of the patients for doctors was too long and inter professional cooperation was lacking, resulting in poor process of care

\section{Outcome of care}

Healthcare professionals perceived the outcome of care as good within the confines of their available resources. The finding of this study is consistent with previous studies ${ }^{35,37}$ which revealed that health professional perceived the outcome of care as good. However, the qualitative component of this study exposes the deep feeling of frustration of many of the health care professional as regards the outcome of care.

Qualitative component augments findings from the quantitative component and explored further the perception of healthcare professionals. However, there were some areas where findings of qualitative component were conflicting with quantitative component. Since qualitative component involved the seniors of different healthcare professions, we strongly believe that the qualitative findings give the true picture of quality of care at the center studied. The disagreement in some of the findings especially in the process of care could be because many Nigerians prefer to be very positive about their institutions except they are probed further. In the qualitative component of the study, the healthcare professionals went on to point out that the inadequacies of structure of care affects their efforts to deliver quality process of care. This is supported by some studies which had shown that suboptimal use of guidelines and poor organizational structure can result in poor process of care ${ }^{38-39}$. In addition, the health care professionals revealed that training a few staffs instead of a team of health professionals can affect communication negatively and hinder effective team work in the process of care. This finding is in agreement with a similar study which shows that lack of resources, structured training, and skills development is a barrier to the implementation of coronary heart disease secondary prevention ${ }^{40}$. Similarly, the participants pointed out the fact that poor staff strength can limit the chances of releasing staffs to go out for training as this may result in overloading the other staffs on ground. This situation is supported by some studies, which have shown that heavy workloads present obstacles to motivation for formal continuing education ${ }^{41-42}$. In the same vein, the outcome of care was considered as suboptimal as outcome was affected by the structure and process of care available ${ }^{43}$.

It is important to note that many of the challenges raised by the participants of this research about quality of care appear to be administrative than health. However, the process of care goes beyond specific health challenges; it also emphasizes the administrative issues e.g. waiting time, record keeping and retrieval which have great impact on quality of care.

Similarly, policy matters in purchase and maintenance of equipment could have a far reaching effect on quality of care. Therefore health professionals need to engage management and administrators effectively in discharge of care for effective outcome. 
The inadequacies in the quality of care highlighted above can be resolved by enforcing compliance with standard guidelines and by encouraging team work among healthcare professionals involved in the care of patients with cardiac diseases. In addition, the healthcare provider to patient ratio can be reviewed and more healthcare workers employed to improve the care given to patients.

\section{Conclusion}

This study reveals that the structure and process of quality of care for patients with heart disease at a Nigerian tertiary hospital was perceived as sub-optimal by the healthcare professionals. However, within the available constraints of resources they were doing their best to improve the outcome of the quality of care given to the patients. There is need for inter professional collaboration and team work to enhance quality of care. Guidelines for cardiac care and quality assurance should be enhanced by the hospital policy.

\section{References}

1. NHS Quality Improvement Scotland. Clinical Standards for Heart disease [Internet]. 2010 [cited 2018]. Available from: https:/www. nhshealthquality.org

2. Fuster V, Kelly B B: Promoting Cardiovascular Health in the Developing World: A Critical Challenge to Achieve Global Health. Institute of Medicine (US) Committee on Preventing the Global Epidemic of Cardiovascular Disease: Meeting the Challenges in Developing Countries. Washington (DC). National Academy press. 2010.

3. Cardiovascular Disease Report [Internet]. World Heart federation. State of the Heart. 2010 [cited 2018] Available from: http://www.worldheartfederation.org/fileadmin/user_upload/documents/WHD2010/FINALStateoftheHeartCVDReport121010.pdf. 2010

4. Allender S, Scarborough P, Peto V, Rayner M Leal J, Luengo-Fernandez R, Gray A. European cardiovascular disease statistics [internet]. British Heart Foundation 2008 Edition [cited 2018]. Available from: https:/www.reserch gate.net

5. Roger VL, Go AS, Lloyd-Jones M, Benjamin EJ, Berry JD, Borden WB, et al. Heart disease and stroke statistics-2012 Update. Circulation. 2012; 125(1):e2-220. doi: 10.1161/CIR.0b013e31823ac046

6. Sliwa K, Damasceno A, Mayosi BM. Epidemiology and etiology of cardiomyopathy in Africa. Circulation. 2005; 112(23):3577-3583. doi: 10.1161/CIRCULATIONAHA.105.542894

7. Onwuchekwa AC, Asekomeh GE. Pattern of heart failure in a Nigerian teaching hospital. Vasc Health Risk Manag. 2009; 5:745-750. https://doi.org/10.2147/VHRM.S6804

8. Soliman EZ, Juma H. Cardiac disease pattern in Northen Malawi: Epidemiologic transition perspective. J Epidemiol.2008;18(5)204-208 9 . Non-communicable diseases country profiles 2011 . WHO Global Report. WHO, Geneva, Switzerland; 2011.

10. Jaarsma T. Interprofessional team approach to patients with heart failure. Heart. 2005; 91(6):832-838. doi: 10.1136/hrt.2003.025296

11. Ouwens M, Wollersheim H, Herens R, Hulscher M, Grol R. Integrated care programmes for chronically ill patients: a review of systematic reviews. Int J Qual Health Care. 2005; 17 (2): 141-146. doi: 10.1093/intqhe/mzi016

12. National heart, lung and blood institute. How is heart disease treated? [Internet]. 2011 [cited 2018]. Available from: http://www.nhlbi.nih. gov/health/health-topics/topics/hhw/

13. Mampuya, W.M. Cardiac rehabilitation past, present and future: an overview. Cardiovasc Diagn and Ther. 2012; 2:1. 38-49. doi: 10.3978/j. issn.2223-3652 2012.01.02

14. Myers J, Prakash M, Froelicher V, Do.D, Partington S, Atwood JE. Exercise capacity and mortality among men referred for exercise testing. N Engl J Med. 2002; 346:793-801. doi:10 1056/NEJMoa011858 15. Warburton DE, McKenzie DC, Haykowsky MJ, Taylor A, Shoemaker P, Ignaszeweski AP, Chan SY. Effectiveness of high intensity interval training for the rehabilitation of patients with coronary artery disease. Am J Cardiol. 2005;95(9):1080-1084. doi:10. 1016/j.amjcard.2004.12.063

16. Lavie CJ, Milani RV. Cardiac rehabilitation, exercise training, and psychosocial risk factors. JACC. 2006; 47(1):212. doi: 10.1016/j. jacc.2005.10.002

17. Wisloff U, Stoylen A, Loennechen JP, Bruvoid M, Rognmo O, Heram PM et al. Superior cardiovascular effect of aerobic interval training versus moderate continuous training in heart failure patients: a randomized study. Circulation. 2007;115(24):3086-3094. doi: 10.1161/ CIRCULATIONAHA.106.675041

18. Hammill BG, Curtis LH, Schulman KA, Whellen DJ. Relationship between cardiac rehabilitation and long-term risks of death and myocardial infarction among elderly Medicare beneficiaries. Circulation 2010;121(1):63-70. doi: 10.1161/CIRCULATIONAHA 109.876383

19. Jolly MA, Brennan DM, Cho L. Impact of exercise on heart rate recovery. Circulation 2011;124(14):1520-1526. doi:101161CIRCULATIONH.10.005009

20. American Heart Association. Your Heart Failure Healthcare Team [internet]. 2012 [cited 2018]. Available from: https:/www.heart.org

21. Key themes and highlights from the national healthcare quality report [Internet]. National Healthcare Report. Agency for Health Care Research and Quality. 2009 [cited 2018]. Available on http://www.ahrq. gov/research/findings/nhqrdr/nhqr08/key.html

22. Grol R. Between evidence based practice and total quality management: The implementation of cost effective care Int J Qual Health Care. 2000 12(4):297-304.

23. Fonarow GC, Gheorghiade M, Abraham WT. Importance of inhospital initiation of evidence-based medical therapies for heart failure - a review. Am J Cardiol. 2004; 94(9):1155-1160. https://doi. org/10.1016/j.amjcard.2004.07.083

24. World Health Organization. Quality of care: a process for making strategic choices in health systems [internet]. Geneva: World Health Organization. 2006. p38 [cited 2018]. Available from: http://www.who. int/iris/handle/10665/43470

25. Heart Failure Model of Care. Department of Health, Western Australia. 2008. Perth: Health Networks Branch, Department of Health, Western Australia.

26. Donabedian A. Evaluating the quality of medical care. Milbank Q. 2005; 83 (4):691-729. doi: 10.1111/j.1468-0009.2005.00397.x

27. Nwosu CB, Princess CC. Caregivers' perception of the quality of child health care services in a general hospital in Lagos state. J. Public Health Epidemiol. 2015;7(2):29-33. doi: 10.5897/JPHE2014.065928. Nnebue CC, Enebe UE, Adinma ED, Iyoke CA, Obionu CN, Ilika AL. Clients' knowledge, perception and satisfaction with quality of maternal health care services at the primary health care level in Nnewi, Nigeria. Niger J Clin Pract. 2014; 17(5):594-601. doi: 10.4103/11193077.14142529. Emelumadu OF, Onyeonoro UU, Ukegbu AU, Ezema $\mathrm{NN}$, Ifeadike $\mathrm{CO}$, Okezie OK. Perception of quality of maternal healthcare services among women utilising antenatal services in selected primary health facilities in Anambra State, Southeast Nigeria. Niger Med J. 2014; 55(2):148-155. doi: 10.4103/0300-1652.129653. 30. Umeano-Enemuoh JC, Onwujekwe OE, Uzochukwu BSC, Ezeoke OP. Patients' satisfaction and quality of care in a tertiary institution in southeast Nigeria. Int. Res. J. Basic Clin. Stud. 2014; 2(2):14-19. http:/ dx.doi.org/10.14303/irjbcs.2014.014

31. Gould D, Drey N, Berridge EJ. Nurses' experiences of continuing professional development. Nurse Educ Today. 2007; 27(6):602-609. doi: 10.1016/j.nedt.2006.08.021

32. Beauchesne, LM, Therrien, Alvarez, N, Bergin L, Burggraf G, Chetaille $\mathrm{P}$, et al. Structure and process measures of quality of care in adult congenital heart disease patients: A pan-Canadian study. 2012; Int J Cardiol. 157(1):70-74. doi: 10.1016/j.ijcard.2010.12.024 
33. Kedward J, DakinL. A qualitative study of barriers to the use of statins and the implementation of coronary heart disease prevention in primary care. Br J Gen Pract. 2003; 53(494): 684-689.

34. Krumholz HM, Baker DW, Ashton CM, Dunbar SB, Friesinger GC, Havrannek EP, et al. Evaluating quality of Care for Patients with heart failure. Circulation. 2000; 101(12): e122-e140. https://doi. org/10.1161/01.CIR.101.12.e122

35. Tyssen R, Palmer KS, Solberg IB, Voltmer E, Frank E. Physicians' perceptions of quality of care, professional autonomy, and job satisfaction in Canada, Norway, and the United States. BMC Health Serv Res. 2013; 13:516. https://doi.org/10.1186/1472-6963-13-516

36. Young RA, Bayles B, Benold TB, Hill JH, Kumar KA, Burge S. Family Physicians' perception on how they deliver cost-effective care: A qualitative study from the residency research network of Texas (RRNeT). Fam Med. 2013; 45(5):311-318.

37. Stanik-Hutt J, Newhouse RP, White KM, Johantegen M, Bass EB, Zangaro G, Wilson R, Fountain L, et al. The quality and effectiveness of care provided by nurse practitioners. J. Nurse Pract. 2013; 9(8):492-500. e13. https://doi.org/10.1016/j.nurpra.2013.07.004

38. Hobbs R. Clinical burden and health service challenges of chronic heart failure.

Br J Gen Pract. 2010; 60(577): 611-615. doi: 10.3399/bjgp10X515133
39. Harantty B, Hibbert D, Mair F, CarlNM, WardNC, CapewellNS, et al. Doctors' perception of palliative care for heart failure: focus group study. BMJ. 2002; 325:581. https://doi.org/10.1136/bmj.325.7364.581

40. Murchie P, Campbell NC, Ritchie LD, Thain J. Running nurse-led secondary prevention clinics for coronary heart disease in primary care: qualitative study of health professionals' perspectives. Br J Gen Pract. 2005; 55(516):522-528.

41. Khomeiran RT, Yekta ZP, Kiger AM, Ahmadi F. Professional competence: factors described by nurses as influencing their development. Int Nurs Rev. 2006; 53(1):66-72. doi: 10.1111/j.1466-7657.2006.00432.x

42. Munro KM. Continuing professional development and the charity paradigm: interrelated individual, collective and organisational issues about continuing professional development. Nurse Educ Today. 2008; 28(8):953-961. doi: 10.1016/j.nedt.2008.05.015

43. Yee J, Unsworth K, Suskin N, Reid RD, Jamnik V, Grace SL. Primary care provider perceptions of intake transition records and shared care with outpatient cardiac rehabilitation programs. BMC Health Serv Res. 2011; 11:231. https://doi.org/10.1186/1472-6963-11-231 